\title{
Substance use by adolescents in special education and residential youth care institutions
}

\author{
Annelies Kepper • Karin Monshouwer • \\ Saskia van Dorsselaer · Wilma Vollebergh
}

Received: 30 August 2010/Accepted: 6 April 2011/Published online: 14 May 2011

(C) The Author(s) 2011. This article is published with open access at Springerlink.com

\begin{abstract}
This study examined substance use rates and related background factors among adolescents in special education (SE) and in residential youth care institutions (RYC). Information on substance use from 531 adolescents in RYC, 603 adolescents in SE for students with behavioral problems (SEB) and 1,905 adolescents in SE for students with learning disabilities (SEL) was compared with information from 7,041 adolescents who attended mainstream education. Results show that substance use rates are particularly high among adolescents in RYC and in SEB. For example, $22 \%$ of the $12-13$ years old in RYC and $16 \%$ in SEB was a daily smoker compared with $1 \%$ of their counterparts in mainstream education. Background factors, including age, ethnic background and family situation, partly explained the differences in substance use between mainstream education on the one hand and SE and RYC on the other hand, but differences between the groups remained substantial and significant. Several interaction effects were found in the relation between SE/RYC and substance use that were all in line with the risk paradox: some subgroups that are normally at lower risk for problem behavior are at higher risk when they are subjected to highrisk indicators. The elevated risk of substance use among adolescents in $\mathrm{RYC} / \mathrm{SE}$ was in some cases particularly marked for those who would normally be at lower risk for substance use (girls in SEB for heavy alcohol drinking and cannabis use, ethnic minority adolescents and adolescents
\end{abstract}

A. Kepper $(\bowtie) \cdot$ K. Monshouwer $\cdot$ W. Vollebergh

Utrecht University, Utrecht, The Netherlands

e-mail: a.s.kepper@uu.nl

K. Monshouwer · S. van Dorsselaer

Trimbos Institute, Netherlands Institute of Mental Health

and Addiction, Utrecht, The Netherlands with a stable family situation in RYC for respectively heavy weekly alcohol drinking and daily use of tobacco). Results of this study have important implications for health education and intervention programs for adolescents in RYC and SE.

Keywords Substance use - Special education . Residential youth care $\cdot$ Risk paradox

\section{Introduction}

Adolescents who are in special education (SE) and/or live in residential youth care institutions (RYC) are characterized by learning disabilities, behavioral and/or emotional problems and appear to be at higher risk for a number of risk behaviors, including problematic substance use $[1,4$, $9,21]$. However, empirical studies on the prevalence of substance use in these groups are scarce. Most large population based studies among adolescents are conducted at mainstream schools, thus targeting only the majority group of adolescents [6, 11, 15]. To our knowledge, only a few studies have been performed on substance use among adolescents in RYC and SE [1, 4, 9, 17, 21]. In general, the results of these studies indicated that levels of substance use in these special groups were indeed (much) higher than in the general population of adolescents. Findings showed that $70 \%$ of US adolescents in SE were currently using cigarettes compared with $36 \%$ in mainstream education [9], among New Zealand boys, $86 \%$ in SE had ever used cannabis compared with $34 \%$ in mainstream education [4] and among Eastern European adolescents aged 14-17 years who live in RYC institutions, $13 \%$ were current cannabis user compared with $2 \%$ use among adolescents in the same age category who live with their parents [1]. More research 
on these subgroups is needed, as most of these studies are outdated $[9,17]$, while more recent studies are quite limited, with very small samples $(n=58)$ [1] that are not representative for the subpopulation of youth in SE [4]. Vaughn [21] investigated substance use among 406 17 years old adolescents in RYC-settings, but did not compare findings with the general population, thus being unable to determine the relative risk of youngsters in youth care settings. In conclusion, the current literature suggests that adolescents in SE and RYC are at an increased risk for problematic substance use. However, up-to-date and representative information on the actual levels of substance use and on the specific impact of risk factors is lacking.

The aim of this study is to examine the substance use among adolescents in SE and RYC in The Netherlands. SE schools provide education for adolescents who are not able to attend mainstream schools owing to a number of problems like emotional and behavioral disorders, learning disabilities and developmental disorders. Within SE, there are subtypes of schools, of which two are included in the present study: schools for adolescents with behavioral problems (SEB) and schools for adolescents with learning disabilities (SEL). Adolescents in RYC are living in residential youth care institutions owing to a variety of family problems and/or mental health and behavioral problems and generally attend SE $[2,10]$.

When analyzing substance use among adolescents in SE and RYC, it is important to take into account of a number of background factors which are related to substance use, i.e., gender, age, ethnic background [5], and family situation [3, 14]. Two effects of these background factors on substance use levels can be discerned. First, subgroups with elevated risks for substance use may be overrepresented in $\mathrm{SE}$ and RYC as compared with the general population. For example, in RYC it is likely that the percentage of children from broken families is substantially higher than among the general population. As children with divorced or separated parents are, in general, at increased risk for substance use [3, 14], this may (partly) explain differences in substance use levels between the adolescents in RYC and in the general population. Second, the relationship of these background factors with substance use levels may be different for adolescents in SE and RYC as compared to their peer groups in the general population. For example, while boys are generally found to be at higher risk for substance use [8], there are indications that the relationship between gender and substance use may be reversed in the SE and RYC-setting. Loeber and Keenan [13] found, for example, that girls with conduct disorders appear to be at higher risk for substance use problems than boys who suffer from conduct disorder, whereas the risk of (heavy) substance use is generally higher for boys. This phenomenon is known as the gender paradox; in some types of disorders or problem behaviors that have an unequal sex ratio, those with the lower prevalence tend to be more seriously affected by high-risk factors [20]. It can be hypothesized that this paradox not only applies to gender, but also might be a more general phenomenon in the interaction of risk factors (risk paradox). Those subgroups that are normally at lower risk for substance use in the general population are at higher risk for substance use when they are subjected to high-risk factors. The present study will investigate this 'risk paradox' for the background variables such as age, gender, ethnic background and family situation. To our knowledge, no former studies have investigated this issue among adolescents in SE and RYC.

For the present study, a dataset is available including information from adolescents in SE, RYC, and mainstream education. The data for these groups were collected according to the same protocol and by using the same measurement instruments. Thus, the present study is well suited in comparing the levels of substance use between adolescents in SE, RYC and mainstream education and in investigating the role of risk and protective factors. In conclusion, the aim of this study is: (1) to generate up-todate information on the prevalence of substance use among two types of high-risk groups: adolescents in RYC and adolescents in $\mathrm{SE}$ and to compare these findings with the results of a sample of mainstream school students, (2) hereby taking into account the demographic background characteristics in these groups and (3) to investigate whether the association between background factors and substance use differs between adolescents in SE/RYC and those in mainstream education.

\section{Methods}

Sample

\section{Residential youth care institutions}

In 2008, there were 48 Dutch RYC institutions, providing 24-h day care for adolescents aged 12-18 years. The Regional Child Welfare Office decides, under the authority of the Dutch juvenile court, whether a minor should be placed in residential care. Approximately, $11 \%$ of the adolescents under the supervision of the Child Welfare Office are placed in RYC institutions every year [10]. In this study, all 48 RYC institutions in The Netherlands were invited to participate in the study. More than half of the institutions $(N=26)$ agreed to cooperate (54\% response). Within each participating institution, all adolescents in the age group of 12-18 years living in a community group were invited to participate and were informed that they would receive a gift voucher of 10 euro if they filled in a 
questionnaire. This procedure resulted in 673 respondents. The response rate on respondent level was $83 \%$. Main reasons of non-response were 'refusing to participate' (30\%) and 'not present due to other obligations' (28\%). Only information regarding the 12-16 age group has been used to compare substance use of adolescents in RYC with adolescents in mainstream schools (in mainstream education, 17 and 18 years old students are not representatives of the Dutch adolescent population, since school is compulsory in The Netherlands only until the age of 16 years). This resulted in a final sample of 531 respondents (92 adolescents aged 12-13 years, 262 adolescents aged 14-15 years and 177 adolescents aged 16 years).

\section{Special education for those with behavioral problems}

Dutch SEB schools are for students who are not able to attend mainstream education due to behavioral problems or emotional disturbance. In 2008, $1.4 \%$ of all Dutch students attended SEB schools [19]. In this study, a multiple-stage random sampling procedure has been used to select the schools. First, 50 SEB schools were drawn from a list of all SEB schools in The Netherlands and were invited to participate. Twenty-two schools agreed to contribute (44\% response). Second, within each participating school, one class from every grade (1-4) was selected randomly from a list of all classes provided by the school. When the selected classes within a school comprised a sample lesser than 35 students, a fifth class was drawn randomly (9 schools). Third, within the classes all students were drawn as a single cluster, resulting in 653 students. The student response rate was $75 \%$. Main reasons for non-response were illness (28\%), refusal to participate $(11 \%)$ and absence due to work experience (34\%). To compare the adolescents in SEB with mainstream students, only those aged 12-16 years were included in the analysis (603 adolescents: 194 adolescents in the age group of 12-13 years, 321 adolescents aged 14-15 years and 88 adolescents aged 16 years).

\section{Special education for those with learning disabilities}

SEL schools provide education for students who have special needs or other learning problems. These students get extra support and are prepared for directly entering the job market after finishing school. In 2008, 14\% of all Dutch students were attending SEL schools [19]. In this study, SEL students were selected through the same procedure as described for the SEB schools (a multiple-stage random sampling procedure). First, 85 schools that provide special education for students with learning problems were invited to participate in the study and 41 schools agreed to collaborate (48\% response). Second, within each participating school, one class from every grade (1-4) was selected randomly from a list of all classes provided by the school. This procedure resulted in 1,965 students (89\% response). Main reasons for the absence were illness $(50 \%)$ and teaching practice $(23 \%)$. Again, only the information of adolescents aged 12-16 years was used which resulted in 1,905 students (652 adolescents aged 12-13 years, 966 adolescents aged 14-15 years and 28716 years old).

For both RYC institutions and SE schools, only minor differences were found between the participating and nonparticipating institutions/schools with respect to region, urbanization, number of students/adolescents, percentage ethnic minorities and percentage adolescents with low SES.

\section{Mainstream education}

To compare the adolescents from RYC and SE with adolescents in mainstream education, data were used from the most recent Dutch National School Survey on Substance Use [15]. The data were collected in October/November 2007, i.e., 1 year prior to the data collection in RYC and SE. For the present study, data of adolescents in the age group of 12-16 years have been used (7,041 adolescents of whom 2,673 adolescents were in the age group of 12-13 years, 3,161 in the age group of $14-15$ years and 1,112 aged 16 years).

\section{Collection of the data}

All data on adolescents in SE and RYC were collected in the fall of 2008. Trained interviewers administered anonymous questionnaires in classes (SE) or living rooms (RYC) and underlined the anonymity of the respondents when introducing and clarifying the questionnaire. The data on students in mainstream education were collected in a similar way in the fall of 2007 [15].

\section{Measures}

\section{Substance use}

Daily use of cigarettes was measured by asking 'Have you ever smoked cigarettes?' Respondents could answer with 'I smoke every day', 'I smoke once in a while, but not every day', 'I have smoked once or twice', 'I used to smoke, but I have quit smoking completely' or 'I have never smoked'. Those answering with 'I smoke every day' were classified as daily smokers.

The number of glasses of alcohol respondents drank every week (Monday to Sunday) was assessed by using the Quantity-frequency measure [7]. Frequency was measured by asking the number of days the adolescent usually drank on weekdays (Monday to Thursday) and weekend days 
(Friday to Sunday). Quantity was measured by asking how many glasses of alcohol the respondent usually drank on a weekday and weekend day. The total average weekly consumption of alcohol was computed by calculating the product of the number of days and the number of glasses and then summing the two products for weekdays and weekend days, resulting in the average total number of glasses per week [12]. This variable was coded as 1 (heavy alcohol use) and 0 (no heavy alcohol use). In order to determine a cut-off score for heavy alcohol use, we assessed the group representing the $15 \%$ highest scores among our sample of 14-15 years old students in mainstream education, for both boys and girls separately. This showed to correspond for boys with drinking ten or more glasses a week and for girls with drinking eight or more glasses of alcohol a week. Hence, in this study boys who drank more than ten alcoholic beverages per week and girls who drank more than eight alcoholic beverages per week were identified as heavy weekly alcohol drinkers.

Lifetime use of cannabis was measured by asking 'How many times did you use cannabis in your life?' Respondents could answer by marking the number of times they had used cannabis $(0,1,2,3,4,5,6,7,8,9,10,11-19$, 20-29, 30-39, 40 times or more). Those answering one time or more were classified as lifetime users of cannabis.

Finally, lifetime use of hard drugs (XTC, cocaine, amphetamine, hallucinogens, GHB, LSD, crack or heroin) was measured by asking 'Have you ever used one of the following drugs during your life'. The respondent could answer with 'yes' or 'no' for every hard drug. Those answering with 'yes' for at least one hard drug were identified as lifetime users of hard drugs.

\section{Background factors}

The following demographic factors were included: gender, age, ethnicity (Dutch/ethnic minority), and family situation (Table 1). Age was recorded into three categories (12-13, 14-15 and 16 years; in Tables 3 and 4 age is analyzed as a continuous variable). Ethnicity was assessed by asking respondent to state their country of birth as well as that of both parents. Those respondents reporting that either he/ she, his/her father or mother was born in a non-western foreign country were classified as belonging to an ethnic minority. Family situation was assessed by asking the respondents if their parents were divorced/separated and if respondents were in contact with their biological mother or father.

\section{Statistical analysis}

The association between substance use and RYC, SEB and SEL respectively and the role of background factors was investigated by using logistic regression analysis. In the first model, the association between substance use (daily use of tobacco, heavy weekly alcohol drinking, lifetime prevalence of cannabis use and lifetime prevalence of hard drug use) and group membership (RYC, SEB, SEL, with mainstream education being the reference group) was tested. In a next step, this association was adjusted for the background factors such as gender, ethnic background, age and marital status of parents. Finally, to investigate a possible interaction between these background characteristics and group membership, the following two-way interaction terms were included: gender $(0=$ girls, $1=$ boys $)$ by respectively RYC, SEB or SEL, age $(0=$ adolescents in the age of 12-13 years, $1=$ adolescents aged 14-16 years) by RYC, SEB or SEL, ethnic background ( $0=$ Dutch, $1=$ ethnic minority) by RYC, SEB or SEL and marital status of parents $(0=$ nondivorced parents, $1=$ divorced parents) by RYC, SEB and SEL. In each of these analyses RYC, SEB, or SEL was coded as 1 and mainstream education was coded as 0 .

All analyses were performed taking into account the fact that the data are clustered, i.e., adolescents from the same class or RYC group were drawn as a single group which results in dependence between observations (adolescents from the same class/group share several characteristics, like having the same teacher or living in the same region). This will influence standard errors and $p$ values. Therefore, robust standard errors were calculated by using the Huber/ White/sandwich estimator as implemented in STATA version 9.1 [18].

\section{Results}

Table 1 illustrates the characteristics of the adolescents in each of the three subgroups. In SEB, there were more boys than girls. In the other groups, the gender distribution was almost equal, although in SEL there were slightly more boys. In RYC, there were more adolescents aged 16 years than in the age group of 12-13 years. In the other groups, it was exactly the opposite: more 12-13 years old and fewer adolescents aged 16 years. The number of adolescents aged 14-15 years was about the same in all the groups (approximately 50\%). Moreover, compared with mainstream education, adolescents in RYC, SEB and SEL more often reported having an ethnic minority background, divorced or separated parents and not being in contact with their biological father or biological mother.

The prevalence of the use of tobacco, alcohol, cannabis and hard drugs by age category is reported in Table 2. Adolescents in RYC, SEB and SEL more often reported daily tobacco use, lifetime cannabis use and lifetime hard drug use compared to adolescents in mainstream education. 
Table 1 Background factors of adolescents in residential youth care institutions, special education for behavioral problems and special education for learning disabilities compared to adolescents in regular education, \%

\begin{tabular}{|c|c|c|c|c|}
\hline Background factors & $\begin{array}{l}\text { RYC \% }(95 \% \mathrm{CI}) \\
N=531\end{array}$ & $\begin{array}{l}\text { SEB } \%(95 \% \mathrm{CI}) \\
N=603\end{array}$ & $\begin{array}{l}\text { SEL \% }(95 \% \text { CI }) \\
N=1,905\end{array}$ & $\begin{array}{l}\text { Mainstream \% }(95 \% \mathrm{CI}) \\
N=6,946\end{array}$ \\
\hline \multicolumn{5}{|l|}{ Gender } \\
\hline Girl & $50.3(43.3-56.8)$ & $18.9(15.9-22.4)$ & $43.7(40.3-47.1)$ & $51.1(49.2-52.9)$ \\
\hline Boy & $49.7(47.1-50.3)$ & $81.1(77.7-84.1)$ & $56.3(43.3-56.8)$ & $48.9(47.1-51.8)$ \\
\hline \multicolumn{5}{|l|}{ Age (years) } \\
\hline $12-13$ & $17.3(13.7-21.6)$ & $32.2(25.0-40.3)$ & $34.2(28.3-40.7)$ & $38.5(33.8-43.3)$ \\
\hline $14-15$ & $49.3(44.2-54.5)$ & $53.2(46.7-59.6)$ & $50.7(45.3-56.1)$ & $45.5(41.4-49.7)$ \\
\hline 16 & $33.3(28.3-38.8)$ & $15.6(10.7-19.6)$ & $15.1(11.5-19.5)$ & $16.0(13.5-18.9)$ \\
\hline \multicolumn{5}{|l|}{ Ethnic background } \\
\hline Dutch & $73.9(69.6-77.7)$ & $74.2(69.8-78.2)$ & $77.7(74.0-81.1)$ & $87.5(85.9-88.9)$ \\
\hline Ethnic minority ${ }^{\mathrm{a}}$ & $26.2(22.3-30.4)$ & $25.8(21.8-30.2)$ & $22.3(19.0-26.0)$ & $12.5(11.1-14.1)$ \\
\hline \multicolumn{5}{|l|}{ Family situation } \\
\hline Divorced/separated parents & $79.7(75.0-83.7)$ & $\mathbf{5 1 . 7}(47.5-55.9)$ & $28.1(25.8-30.6)$ & $18.3(17.3-19.4)$ \\
\hline No contact with biological mother & $10.7(8.6-13.4)$ & $4.8(3.3-6.9)$ & $3.3(2.6-4.2)$ & $1.2(1.0-1.5)$ \\
\hline No contact with biological father & $35.2(31.1-39.5)$ & $15.9(13.2-19.1)$ & $9.8(8.5-11.4)$ & $4.6(4.1-5.2)$ \\
\hline
\end{tabular}

In RYC, the rates were the highest, although differences with SEB were sometimes small (e.g., the lifetime prevalence of hard drug use among the 12-13 years old was around $13 \%$ in both RYC and SEB). The differences in substance use between RYC, SEB and-to a lesser degree SEL-mainstream education were particularly marked in the youngest group (12-13 years). For example, of the 12-13 years old in RYC, $22 \%$ reported daily tobacco use and $33 \%$ lifetime cannabis use. The latter is eight times higher compared to adolescents of the same age in mainstream education. But also among the older adolescents, the differences were large, with four times more hard drug users in RYC and SEB (both 31\%) than in mainstream education $(7 \%)$.

Table 3 reports the results of the logistic regression analysis on the association between substance use and group membership (RYC, SEL, SEB and mainstream education (reference category). The unadjusted model illustrates that being in RYC involved a higher risk of daily tobacco use and - to a lesser degree- heavy weakly alcohol use, lifetime prevalence of cannabis and hard drug use. Being a student in SEB also increased the risk of substance use, but these associations were less strong. For example, being in RYC involved a higher risk of daily use of tobacco (OR $=16.91$, $\mathrm{CI}=13.14-21.76)$ compared to mainstream education, than being in SEB (OR $=6.74, \mathrm{CI}=5.01-9.06)$. Finally, SEL students had a greater risk of being a daily tobacco user and a hard drug user compared to adolescents in mainstream education. There were no significant differences between
SEL students and mainstream education students in being a heavy weekly alcohol user or a cannabis user. In the second model, adjusting the analyses for gender, ethnic background, age and marital status, all associations between substance use and group membership became somewhat weaker (except for daily use of tobacco in SEL), though remaining significant. For example, being in RYC still involved a high risk for daily smoking, also when background factors were taken into account ( $\mathrm{OR}=10.40, \mathrm{CI}=7.90-13.71)$. The risk of daily tobacco use due to being in SEB declined only slightly when adjusting for the background factors $(\mathrm{OR}=6.70, \mathrm{CI}=4.99-9.01)$.

Four interaction terms of being in RYC, SEB or SEL and background factors were found to be significant $(p<0.001)$ : a marital status of parents by RYC interaction for daily use of tobacco $(\mathrm{OR}=0.43, \mathrm{CI}=0.27-0.67)$, an ethnic background by RYC interaction for heavy weekly drinking ( $\mathrm{OR}=2.72, \quad \mathrm{CI}=1.47-5.03)$ and $\mathrm{a}$ gender by SEB interaction for both heavy weekly drinking $(\mathrm{OR}=0.29, \mathrm{CI}=0.16-0.53)$ and lifetime use of cannabis $(\mathrm{OR}=0.36, \mathrm{CI}=0.24-0.54)$.

Post estimation analyses of these interaction effects are reported in Table 4. Among adolescents in RYC whose parents were divorced or separated, the risk of being a daily smoker was higher compared to their counterparts in mainstream education $(\mathrm{OR}=7.81, \quad \mathrm{CI}=5.76-10.59)$. However, among adolescents whose parents were not divorced or separated, the risk of being a daily smoker was even more elevated for those in RYC $(\mathrm{OR}=18.18$, 


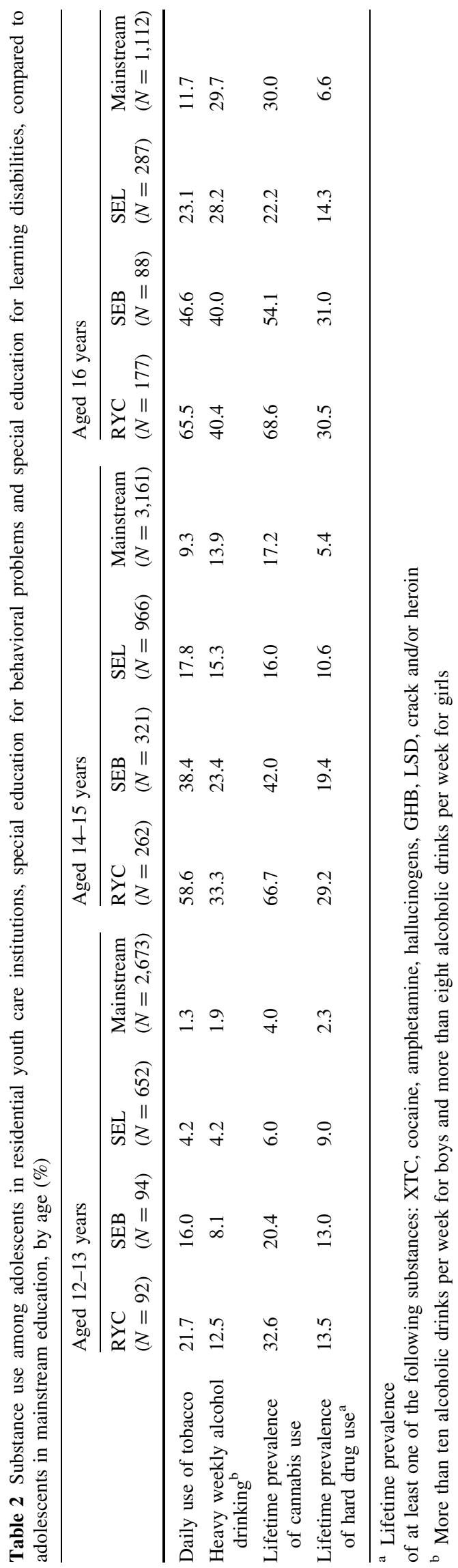

$\mathrm{CI}=11.87-27.85)$. The risk of heavy weekly drinking among Dutch adolescents in RYC was somewhat higher as compared to those in mainstream education $(\mathrm{OR}=1.81$, $\mathrm{CI}=1.33-2.45)$; however, among ethnic minorities, this risk was more elevated ( $\mathrm{OR}=4.92, \mathrm{CI}=2.72-8.90)$. Boys in SEB were not significantly at higher risk for heavy weekly drinking as compared to boys in mainstream education; however, for girls in SEB the risk of heavy weekly drinking was much higher as compared to girls in mainstream education $(\mathrm{OR}=5.05, \mathrm{CI}=2.95-8.67)$. Finally, boys in SEB were at higher risk for cannabis use $(\mathrm{OR}=2.36$, $\mathrm{CI}=1.83-3.06)$ compared to those in mainstream education, but the risk of cannabis use was even more elevated among girls in SEB $(\mathrm{OR}=6.57, \mathrm{CI}=4.28-10.10)$.

\section{Discussion}

Main findings

Substance use rates are particularly high among adolescents living in RYC institutions. Especially, daily tobacco use was highly prevalent, with more than 20 times as many daily smokers among adolescents aged 12-13 years in RYC as compared to those in mainstream education. Being in RYC also increased the risk of lifetime prevalence of cannabis use, hard drug use and-to a smaller degreeheavy weekly drinking in comparison with those in mainstream education. In addition, elevated substance use rates among adolescents who are in SE due to behavioral problems (SEB) were found for all investigated types of substance use. Daily tobacco use and lifetime prevalence of hard drug use, among adolescents in SE for learning disabilities (SEL) were also higher compared to those in mainstream education, although differences were less pronounced as for those in SEB or RYC. Differences in substance use rates between the three risk groups and mainstream education were particularly large in the youngest age category (12-13 years old).

Background factors, including age, ethnic background and family situation, partly explained the differences in substance use between mainstream education on the one hand and SE and RYC on the other hand, but all differences between the groups remained substantial and significant. Four significant interactions were found in the relationship between SE/RYC and substance use that were in line with the risk paradox: the elevated risk of substance use in SE/RYC was particularly noticeable among adolescents who are normally at lower risk for substance use (i.e., in SEB, girls for heavy alcohol drinking and cannabis use, and in RYC, ethnic minority adolescents for heavy weekly alcohol use and adolescents with a stable family situation for daily tobacco use). 
Table 3 Association between daily use of tobacco, lifetime prevalence of cannabis use and hard drugs use and risk groups, adjusted for background factors, odds ratios (OR)

\begin{tabular}{|c|c|c|c|c|c|c|c|c|}
\hline \multirow[t]{2}{*}{ Variable } & \multicolumn{2}{|c|}{$\begin{array}{l}\text { Daily use } \\
\text { of tobacco }\end{array}$} & \multicolumn{2}{|c|}{$\begin{array}{l}\text { Heavy weekly } \\
\text { alcohol drinking }\end{array}$} & \multicolumn{2}{|c|}{$\begin{array}{l}\text { Lifetime prevalence } \\
\text { of cannabis use }\end{array}$} & \multicolumn{2}{|c|}{$\begin{array}{l}\text { Lifetime prevalence } \\
\text { of hard drug use }\end{array}$} \\
\hline & OR & $95 \% \mathrm{CI}$ & OR & $95 \% \mathrm{CI}$ & OR & $95 \% \mathrm{CI}$ & OR & $95 \% \mathrm{CI}$ \\
\hline \multicolumn{9}{|l|}{ Model $1^{\mathrm{a}}$} \\
\hline $\mathrm{RYC}^{\mathrm{c}}$ & $16.91 *$ & $13.14-21.76$ & $3.55^{*}$ & $2.75-4.58$ & $9.63 *$ & $7.70-12.06$ & $8.10 *$ & $6.37-10.32$ \\
\hline $\mathrm{SEB}^{\mathrm{c}}$ & $6.74 *$ & $5.01-9.06$ & $2.00 *$ & $1.46-2.74$ & $3.53 *$ & $2.70-4.62$ & $5.14 *$ & $3.95-6.67$ \\
\hline $\mathrm{SEL}^{\mathrm{c}}$ & $2.29 *$ & $1.77-2.95$ & 1.16 & $0.89-1.52$ & 0.95 & $0.76-1.18$ & $2.60 *$ & $2.06-3.28$ \\
\hline \multicolumn{9}{|l|}{ Model $2^{\mathrm{b}}$} \\
\hline $\mathrm{RYC}^{\mathrm{c}}$ & $10.40 *$ & $7.90-13.71$ & $2.28 *$ & $1.70-3.05$ & $5.50 *$ & $4.33-6.99$ & $5.55^{*}$ & $4.23-7.27$ \\
\hline $\mathrm{SEB}^{\mathrm{c}}$ & $6.70 *$ & $4.99-9.01$ & $2.06^{*}$ & $1.51-2.81$ & $3.00 *$ & $2.34-3.85$ & $4.31 *$ & $3.30-5.62$ \\
\hline $\mathrm{SEL}^{\mathrm{c}}$ & $2.32 *$ & $1.83-2.93$ & 1.21 & $0.96-1.52$ & 0.86 & $0.71-1.05$ & $2.45^{*}$ & $1.93-3.09$ \\
\hline Male $^{\mathrm{d}}$ & 0.88 & $0.76-1.03$ & 1.00 & $0.86-1.17$ & 1.16 & $1.02-1.31$ & 1.18 & $1.00-1.39$ \\
\hline Ethnic minority ${ }^{\mathrm{e}}$ & $0.64 *$ & $0.52-0.79$ & $0.48^{*}$ & $0.38-0.60$ & 0.89 & $0.75-1.06$ & 1.10 & $0.89-1.35$ \\
\hline Age (in years) & $1.81 *$ & $1.69-1.94$ & $2.23 *$ & $2.09-2.39$ & $1.86^{*}$ & $1.75-1.97$ & $1.34 *$ & $1.25-1.44$ \\
\hline Divorced parents $^{f}$ & $1.95^{*}$ & $1.68-2.27$ & $1.35^{*}$ & $1.16-1.58$ & $2.01 *$ & $1.75-2.31$ & $1.39 *$ & $1.15-1.68$ \\
\hline
\end{tabular}

$* p<0.001$

a Model 1: unadjusted

b Model 2: adjusted for all other variables in the model

${ }^{c}$ Reference group is mainstream education

${ }^{\mathrm{d}}$ Reference group is female

e Reference group is Dutch

${ }^{\mathrm{f}}$ Reference group is non divorced parents

Table 4 Association between substance use and risk groups among girls and boys, Dutch adolescents and ethnic minorities and adolescents with divorced parents and nondivorced parents, odds ratios (OR)

\begin{tabular}{|c|c|c|c|c|}
\hline & OR & $95 \% \mathrm{CI}$ & OR & $95 \% \mathrm{CI}$ \\
\hline \multicolumn{5}{|l|}{ Daily use of tobacco } \\
\hline & \multicolumn{2}{|c|}{ Divorced parents } & \multicolumn{2}{|c|}{ Nondivorced parents } \\
\hline Mainstream education (reference) & 1 & - & 1 & - \\
\hline RYC & $7.81^{*}$ & $5.76-10.59$ & $18.18 *$ & $11.87-27.85$ \\
\hline \multicolumn{5}{|l|}{ Heavy weekly alcohol drinking } \\
\hline & \multicolumn{2}{|c|}{ Dutch adolescents } & \multicolumn{2}{|c|}{ Ethnic minorities } \\
\hline Mainstream education (reference) & 1 & - & 1 & - \\
\hline \multirow[t]{2}{*}{ RYC } & $1.81^{*}$ & $1.33-2.45$ & $4.92^{*}$ & $2.72-8.90$ \\
\hline & Boys & & \multicolumn{2}{|l|}{ Girls } \\
\hline Mainstream education (reference) & 1 & - & 1 & - \\
\hline SEB & 1.48 & $1.04-2.08$ & $5.05^{*}$ & $2.95-8.67$ \\
\hline \multicolumn{5}{|l|}{ Lifetime prevalence of cannabis use } \\
\hline & Boys & \multicolumn{3}{|c|}{ Girls } \\
\hline Mainstream education (reference) & 1 & - & 1 & - \\
\hline SEB & $2.36^{*}$ & $1.83-3.06$ & $6.57^{*}$ & $4.28-10.10$ \\
\hline
\end{tabular}

$* p<0.001$

Prevalence of substance use in the high-risk groups

Our results are consistent with findings of previous studies that showed high prevalences of substance use among adolescents who attend SE schools [4, 9]. As in our study, SE students in both New Zealand and US reported elevated rates of substance use compared to students in mainstream education. In addition, previous studies that found high 
substance use rates in RYC-settings [1, 21] are confirmed by our results. For example, Vaughn and colleagues [21] investigated substance use among 17 years old adolescents who live in a RYC-setting and found that almost half of these adolescents (46\%) had ever used marijuana. Although the present study investigated a younger group, the number of adolescents who used cannabis was even higher (almost $70 \%$ of the 16 years old in RYC had used cannabis at least once). In addition, the percentage of heavy alcohol users (consuming more than ten alcoholic drinks per week for boys and more than eight alcoholic drinks per week for girls) was much higher in SEB and RYC compared to mainstream education. About $40 \%$ of the adolescents aged 16 years in SEB and RYC and SEL reported to drink more than ten or eight glasses of alcohol per week. This is comparable to the average amount of alcoholic beverages Dutch adults' drink [22].

Though the present study found an increased risk for substance use among adolescents with learning disabilities, this risk was not as elevated as compared to adolescents in RYC or SEB. Adolescents in SEL are not able to attend mainstream education because they have difficulties with their learning abilities, whereas adolescents in SEB attend SE due to a whole range of problems: emotional disturbance, behavioral problems and, or family problems. Apparently, learning problems as such are less strongly associated with substance use.

\section{The role of background factors}

In line with previous studies on substance use, this study found that ethnic minorities [21], younger adolescents [1] and adolescents in intact families [3,14] were less likely to use substances. As shown in Table 1, the percentage of broken families was much higher in RYC and, to a lesser extent in $\mathrm{SE}$, as compared to mainstream education. Therefore, the high prevalence of substance use in RYC and SE can partially be attributed to the high number of adolescents with an unstable family situation.

\section{Risk paradox}

Several interaction effects between risk factors were found, that are in line with the assumptions of the risk paradox: the elevated risk of substance use among adolescents in RYC/SE was in some cases particularly marked for those who would normally be at lower risk for substance use (i.e., girls, ethnic minorities and adolescents with a stable family situation). We can think of two explanations for these findings. First, those normally at lower risk (e.g., children from intact families) are generally living in more protective environments. The threshold for entering the RYC-setting might accordingly be higher-due to more resources in these families for coping with their child's problems without professional help-and therefore, higher levels of problem behavior in the children who are finally brought into these RYC-settings may prevail. Thus, elevated levels of problem behavior in children in RYC originating from these settings are to be expected. Moreover, Loeber and Keenan [13] noted in their review report that despite the lower prevalence of disruptive disorders in girls compared to boys, girls who do suffer from conduct disorder are at higher risk for developing comorbid conditions like substance use. They hypothesized that since girls have a higher threshold for problematic behavior or physical disorders than boys, they consequently require more harmful risk factors to develop problem behavior than boys. Following this hypotheses, it can be theorized that girls have a higher threshold for attending SEB schools and therefore have more complex and serious behavioral problems including the use of cannabis and excessive use of alcohol if they do attend SE schools.

Second, we can hypothesize that being in SE-settings has a levelling effect on the problem behavior of all children entering these settings-due to the effects of peer influence within these groups, and due to being in these settings as such. These effects may be particularly elevated in the groups normally at lower risk as well, because entering these settings brings them into contact with higher risk groups. Ethnic minority children may serve as an example in this respect. It is a well-known fact that ethnic minority children are usually at (far) lower risk for drinking alcohol-due to the protective effect of restrictive parenting and cultural values forbidding alcohol in these groups [23]. Entry to a group of high-risk peers-who tend to drink heavily - may have a particularly strong effect on children originating from an ethnic minority background. Future studies analyzing peer processes in these settings are needed to test these assumptions.

\section{Strength and limitations}

A major strength of the current study is that the methodology was the same for RYC, SE and mainstream education. This makes the comparison of high risk groups with adolescents in mainstream education more valid. Possible limitations have to be taken into account. First, analyses were based on self-report data which could result in overor under-reporting of substance use. But as the administration of the questionnaires in school classes and living rooms occurred under the supervision of a trained interviewer and anonymity was assured, self-report is assumed to be reliable [16]. Second, there is a possible under-representation of substance users due to the number of adolescents - in particular in RYC and SEB - that refused to cooperate. It can be expected that the number of substance 
users is especially high among these refusers. Third, since the study is based on a cross-sectional design, inferences on causal relationships cannot be made. Fourth, other nonassessed factors can possible also account for much of the elevated risk (family problems, deviant peers, delinquency, school problems) and therefore have to be taken into consideration in future studies.

In conclusion, this study found high rates of substance users among adolescents in RYC institutions and SE, in particular SEB, compared to adolescents in mainstream education. These results confirm that adolescents in these settings are not only at higher risk for psychosocial problems, but also at higher risk for developing substance use disorders. These differences are only partially explained by other risk factors that are elevated in this group (e.g., coming from broken families). Acknowledging these risks is of major importance for prevention and treatment programmes directed at these groups, as high levels of substance use may have a considerable impact on the success of these programmes. Results of this study have important implications for health education and intervention programs for adolescents in RYC institutions and in adolescents in SE. It is important to develop substance use prevention programmes that target high-risk adolescents in SE and RYC.

Open Access This article is distributed under the terms of the Creative Commons Attribution Noncommercial License which permits any noncommercial use, distribution, and reproduction in any medium, provided the original author(s) and source are credited.

\section{References}

1. Bacovic D, Marinkovic JA, Grujicic S, Maksimovic M (2006) Differences in substance use patterns among youths living in foster care institutions and in birth families. Drugs Educ Prev Pol $13: 341-351$

2. Baker AJL, Kurland D, Curtis P, Alexander G, Papa-Lentini C (2007) Mental health and behavioral problems of youth in the child welfare system: residential treatment centers compared to therapeutic foster care in the Odyssey project population. Child Welfare 86:97-123

3. Bjarnason Th, Davidaviciene AG, Miller P, Nociar A, Pavlakis A, Stergar E (2003) Family structure and adolescent cigarette smoking in eleven European countries. Addiction 98:815-824

4. Denny SJ, Clark TC, Watson RD (2004) The health of alternative education students compared to secondary school students. NZ Med J 117:1-12

5. Donovan JE (2004) Adolescent alcohol initiation: a review of psychosocial risk factors. J Adolesc Health 35:529

6. Dorsselaer S, Zeijl E, Eeckhout S, Ter Bogt T, Vollebergh W (2007) HBSC 2005: gezondheid en welzijn van jongeren in Nederland. [Health behaviour in school-aged children 2005: young people's health and well-being in The Netherlands]. Trimbos-instituut, Utrecht
7. Engels RCME, Knibbe RA (2000) Alcohol use and intimate relationships in adolescence: when love comes to town. Addict Behav 25:435-439

8. Fisher LB, Miles IW, Austin SB, Camargo CA Jr, Colditz GA (2007) Predictors of initiation of alcohol use among US adolescents: findings from a prospective cohort study. Arch Pediat Adolesc Med 161:959-966

9. Grunbaum JA, Lowry R, Kann L (2001) Prevalence of healthrelated behaviors among alternative high school students as compared with students attending regular high schools. J Adolesc Health 29:337-343

10. Harder AT, Knorth EJ, Zandberg T (2006) Residentiële jeugdzorg in beeld [Residential child and youth care in the picture]. SWP Publishers, Amsterdam

11. Hibell B, Guttormsson U, Ahlström A, Balakireva O, Bjarnason T, Kokkevi A, Kraus L (2009) The 2007 ESPAD Report-substance use among students in 35 European countries. The Swedish Council for Information on Alcohol and Other Drugs (CAN), Stockholm

12. Koning IM, Vollebergh WAM, Smit F, Verdurmen JEE, Van Den Eijnden RJJM, Ter Bogt TFM, Stattin H, Engels RCME (2009) Preventing heavy alcohol use in adolescents (PAS): cluster randomized trial of a parent and student intervention offered separately and simultaneously. Addiction 104:1669-1678

13. Loeber R, Keenan K (1994) Interaction between conduct disorder and its comorbid conditions: effects of age and gender. Clin Psychol Rev 14:497-523

14. McArdle P, Wiegersma A, Gilvarry E, Kolte B, McCarthy S, Fitzgerald M, Brinkley A, Blom M, Stoeckel I, Pierolini A, Michels I, Johnson R, Quensel S (2002) European adolescent substance use: the roles of family structure, function and gender. Addiction 97:329-336

15. Monshouwer K, Verdurmen J, van Dorsselaer S, Smit E, Gorter A,Vollebergh W (2008) Jeugd en riskant gedrag 2007 [Youth and risk-taking behaviour 2007]. Trimbos-instituut, Utrecht

16. Smit F, de Zwart W, Spruit I, Monshouwer K, van Ameijden E (2002) Monitoring substance use in adolescents: school survey or household survey? Drugs Educ Prev Pol 9:267-274

17. Stam H, Mensink C and de Zwart WM (1998) Jeugd en riskant gedrag 1997. Roken, drinken, drugsgebruik en gokken in het voortgezet speciaal onderwijs [Youth and risk-taking behaviour 1997: smoking, drinking and drug use in special eduaction]. Trimbos-instituut, Utrecht

18. Stata Corporation (2005) Stata Release 9. Stata Press, College Station, Texas

19. Statistics Netherlands (2007) Jaarboek onderwijs in cijfers 2008 [Year report Education in numbers 2008]. Centraal Bureau voor de Statistiek, Heerlen

20. Taylor DC, Ounsted C (1972) The nature of gender differences explored trough ontogenetic analysis of sex ratios in disease. In: Ounsted C, Taylor DC (eds) Gender differences: their ontogeny and significance. Churchill Livingstone, London, pp 215-240

21. Vaughn MG, Ollie MT, McMillen JC, Scott L Jr, Munson M (2007) Substance use and abuse among older youth in foster care. Addict Behav 32:1929-1935

22. Verdurmen, J, Monshouwer K, Dorsselaer S (2003) Bovenmatig drinken in Nederland [Excessive drinking in The Netherlands]. Bureau NDM, Utrecht

23. Wallace JM, Brown TN, Bachman JG, Laveist TA (2003) The influence of race and religion on abstinence from alcohol, cigarettes and marijuana among adolescents. J Stud Alcohol 64:843-848 